\title{
From New Democracy to Socialism with Chinese Characteristics in a New Era -Commemorating the 70th Anniversary of the Founding of New China
}

\author{
He Hua
}

Mianyang Normal University Marxist college, Mianyang, Sichuan, China

\begin{abstract}
Key Words: new democracy; new era; socialism with Chinese characteristics
\end{abstract}
\begin{abstract}
People Republic of China, Chinese society has experienced the process of building from a new democratic society to socialism with Chinese characteristics in a new era. It is the evolution of socialist China from choice, establishment to continuous development. It is also the course of continuous exploration and development of the socialist road with Chinese characteristics. It has brought us a lot of enlightenments, that is, adhering to the guiding position of Marxism, constantly promoting the sinicization and timization of Marxism, strengthening Chinese cultural self-confidence, constantly promoting reform and innovation, and maintaining strategic determination, firmly following the road of socialism with Chinese characteristics, coordinating internal and external development, constantly enhancing the well-being of the people, strengthening party leadership, and coordinating the "two great revolutions."
\end{abstract}

\section{从新民主主义到新时代中国特色社会主义 一纪念新中国成立 70 周年}

\author{
何花 \\ 绵阳师范学院马克思主义学院, 绵阳, 四川, 中国 \\ email: cqhh88@126.com \\ 通讯作者
}

关键词：新民主主义; 新时代; 中国特色社会主义

摘要: 新中国成立以来, 中国社会经历了从新民主主义社会到新时代中国特色社会主义的发 展演变, 它是中国社会不断发展变迁的历程, 也是中国特色社会主义道路不断探索发展壮大 的历程。它带给我们诸多经验与启示, 即把科学社会主义原则和中国社会实际有机结合; 正 确处理文化建设与经济政治的关系; 坚定 “四个自信” ; 坚定走自己的道路; 实现国家复兴 和人民幸福有机统一; 正确推进“两个伟大革命”。

\section{1.引言}

习近平在庆祝改革开放四十周年大会上提出近代以来实现中华民族伟大复兴的三大里程碑, 其中，成立中华人民共和国是最伟大的里程碑之一。新中国的成立，开启了中国社会由革命 到建设的主题。毛泽东在新中国成立前夕曾经指出, “我们不但善于破坏一个旧世界, 我们 还将善于建设一个新世界”[1]。新中国成立后, 为了建设新中国, 探索中国自己的建设和发 
展道路, 党和人民前赴后继不断努力, 经过 70 年的接续奋斗, 终于找到了自己的道路。它 经历了建国初期的新民主主义社会，到传统社会主义模式、中国特色社会主义新时期，直至 进入新时代中国特色社会主义，其间有很多经验教训值得我们总结。本文试图对此作一梳 理，以此纪念新中国成立 70 周年。

\section{2.新中国成立以来中国社会发展的轨迹}

\section{1 新民主主义社会的构建及向社会主义的过渡}

中国特色社会主义始于毛泽东的新民主主义社会论。[2]新民主主义社会是马克思主义与 中国实际相结合的光辉典范和伟大创造，它是破解近代中国困局、适合中国情形的最佳选择 方案。中国进入近代社会后, 面临向何处去的困境。先进中国人士经历了不断探索, 先后从 经济技术、政治制度、思想文化体系学习西方。但历史证明，中国社会选择走资本主义道路 行不通。俄国十月革命一声炮响, 给我们送来了马克思列宁主义, “走俄国人的道路, 这就 是结论。”中国共产党成立后, 我们把马克思列宁主义作为我们党的指导思想, 把社会主义 作为我们党的奋斗目标和前途。但是，党对于如何走向社会主义，中间需要经历哪些环节和 步骤, 采取哪些手段等等, 我们党在成立之初并不十分清楚。到了抗日战争时期, 以毛泽东 为代表的中国共产党人, 根据丰富的斗争实践经验和国内阶级斗争力量对比的变化, 提出革 命胜利后建立新民主主义共和国，创立了新民主主义社会理论。它为我们建设工业化、走向 社会主义、摆脱“挨打”的命运起了重要作用。

新民主主义社会理论，阐述了新中国成立后中国应该建立什么样的社会、走什么样的发 展道路等问题。新民主主义社会的建设方案，为后来通向社会主义、继而探索中国特色社会 主义建设模式创造了物质条件和政治前提。它是中国共产党人自主探索、总结、创造出来 的，既不同于苏联社会主义模式，也不同于西方资本主义模式，毛泽东指出它是“过渡的形 式，但是不可移易的必要的形式”。[3] 它是向社会主义过渡的模式，是“新式的资本主义”， 体现了中国共产党人实事求是的创新精神, 解决了象中国这样经济文化落后的东方大国如何 由农业国走向工业国的问题。通过发展一段时间新式资本主义经济，不断增强和壮大社会主 义的物质力量, 增加社会主义因素, 为向社会主义过渡创造条件。

关于新民主主义社会存在的时间，毛泽东曾经估计要“一百年”。[4]斯特朗也曾提到毛泽 东对新民主主义社会存在时间的估计问题，她指出，毛泽东说它将长时期存在。[5]后来，毛 泽东又提出了“三年准备，十年计划经济建设”[6]设想，即主张用三年时间把国民经济恢复以 后，再搞十年新民主主义社会建设，然后再向社会主义过渡。关于新民主主义社会向社会主 义过渡的条件，毛泽东指出，由于中国要在政治经济上完成民主革命，较之俄国要困难得 多, 需要更多时间和努力, 因此, “不到具备了政治上经济上一切应有的条件之时, 不到转 变对于全国最大多数人民有利而不是不利之时, 不应当轻易谈转变。”[7]刘少奇也指出, 要 让新民主主义社会发展一段时间，到条件成熟了再向社会主义过渡。

但是，到 1952 年 6 月，“三反”、“五反”取得了决定性胜利，毛泽东指出不应再将民族 资产阶级称为中间阶级。[8]这意味着对民族资本主义由利用、限制到改造的态度变化。1952 年 9 月 24 日, 毛泽东在中共中央书记处会议上提出, 我们要在“十年到十五年基本上完成社 会主义, 不是十年以后才过渡到社会主义”。 ${ }^{[9]} 1952$ 年底, 我国国民经济达到解放前的最高 水平，工农业总产值(按 1952 年不变价格计算)比 1949 年增长了 $77.5 \%$ 。[10]党中央开始酝 酿并于 1953 年正式提出党在过渡时期的总路线，标志着我国进入社会主义过渡时期。1956 年底, 党又宣布社会主义改造完成, 我们进入了社会主义建设时期, 新民主主义社会至此结 束。改革开放后，有人认为新民主主义社会过早结束，社会主义社会过早过渡，因此提出社 会主义初级阶级是对新民主主义发展模式的复归 ${ }^{[11]}$ 。但是，正如邓小平所指出，“建国头七 年的成绩是大家一致公认的, 我们的社会主义改造是搞得成功的, 很了不起。”经过社会主 
义改造，我国最终走向社会主义社会。

新民主主义社会实质上是一种混合发展模式。虽然国营经济在国民经济中起领导作用, 政治上实行人民民主专政，思想文化上以马克思主义为指导，但是资本主义因素和社会主义 因素并存，农村个人所有制经济和城乡个体经济比重还很大，整个社会还没有确立起公有制 为主体的经济制度。但是, 由于个体经济和私有经济的存在不利于当时国家工业化建设, 影 响农村农业和国家现代化的发展，所以它很快被中止，我国社会进入社会主义改造。社会主 义改造时间比较短, 而且还存在“四过”问题。但是, 从新民主主义向社会主义过渡, 是中国 社会走向社会主义的必由之路, 实践证明是正确的道路, 它为我国确立社会主义制度奠定了 物质基础和政治条件，为实现我国社会“站起来”打下了坚实基础。新民主主义社会建设时间 虽然短暂, 但它却给我们留下了宝贵经验教训, 这需要在后来的发展中不断加以总结、继 承、改正和发展。

\section{2 从选择苏联模式社会主义向中国特色社会主义的初步探索}

从新民主主义向社会主义过渡时期, 我们党实行把社会主义改造和社会主义建设同时并 举的方针。在“一边倒”外交政策下, 新中国打破了帝国主义阵线封锁, 掀起了学习苏联社会 主义的热潮。一方面, 这与我们既定的发展目标相吻合, 另一方面, 也与苏联建设的伟大成 就不断鼓舞我们有关。1952 年苏联联共 19 大上, 马林科夫宣布, 依靠农业集体化, 苏联小 麦产量比 1940 年增长 $48 \%$, 使过去认为是最尖锐、最严重的粮食问题, 成功而永远地解决 了。对此, 毛泽东指出, 我们也只有用有计划地领导和发展农业合作化的方法才能解决我国 粮食问题。[12]我们党提出要好好“学习苏联”的号召, 毛泽东指出苏联共产党“在列宁和斯大 林的领导下, 不但会革命, 也会建设。---我们必须向他们学习”, 要“恭恭敬敬地学, 老老实 实地学” [13]。1952 年 10 月, 中国举办了“中苏友好月”活动, 掀起了全面学习苏联的高潮。 此后，“苏联的今天就是我们的明天”、“向苏联老大哥学习”成了风气。在苏联技术援助和专 家指导下, 我国工业呈现欣欣向荣发展景象, 156 项援建项目, 为我国工业化建设打下了初 步基础。

但是，学习苏联过程中，我们存在照抄照搬问题。中宣部在关于过渡时期总路线的宣传 提纲中写道: “资本主义国家从发展轻工业开始, 一般是花了 50 年到 100 年的时间才能实现 工业化, 而苏联采用了社会主义工业化的方针, 从重工业建设开始, 在十多年中 (从 1921 年开始到 1932 年第一个五年计划完成) 就实现了国家的工业化。苏联过去所走的道路正是 我们今天要学习的榜样。”[14]受此影响, 我们也选择了优先发展重工业的工业化发展模式。 为祝贺十月革命 36 周年, 毛泽东给马林科夫的电报中把苏联称作“就像灯塔一样照耀着全世 界被剥削人民和被压迫民族的前进道路”, 并明确表示, 我们正“沿着苏联所胜利地走过的社 会主义工业化和国民经济的社会主义改造的光荣道路上前进”。[15]学习苏联虽然是当时我们 的必然选择，但是，它却使中国社会主义深深打上了苏联模式烙印，为后来我们艰难突破苏 联模式、探索自己社会主义道路埋下了伏笔。

为什么当时要选择苏联社会主义模式? 毛泽东后来指出, 因为那时我们对搞建设是懵懜 懂懂的, 完全没有经验, 只好硬搬, 但也让人“觉得不满意, 心情不舒畅”。[16]苏共二十大以 前, 党中央早已觉察到苏联模式的弊端并试图加以纠正。据薄一波同志回忆, 党在 1955 年 底就提出了“以苏为鉴”的问题 117$]$ 。但是，如何“以苏为鉴”，探索自己社会主义建设道路，却 在目标模式上没有根本突破, 只是把全面学习转入以借鉴为主, 当然, 这也“是一种摒弃苏 联实践的落后面的有高度选择性的方式去学习”。[18]这表明我们在学习别人方面有了选择。 毛泽东提出, 要坚持把马克思主义的普遍真理同中国具体实际“第二次”结合, 以此探索自己 社会主义建设道路。党的八大前后, 中国社会主义探索进入良好开端。

但是，由于受“左”倾思想影响，中国社会主义建设道路探索并不平坦，中间经历了“大 跃进”和“文化大革命”两次错误, 使社会主义建设陷入困境。诚然, 中国特色社会主义初次 
探索并不成功, 但它是在自力更生基础上进行的自主试验, 并没有消极被动的等待, 为后来 的探索提供了反面教训, 避免掉入苏东多米诺骨牌效应的命运。中国社会主义建设正反两方 面经验教训, 事实上为中国特色社会主义再次探索打下了基础。它告诉我们, 中国社会主义 建设必须根据中国实际和时代特征, 与时俱进推进马克思主义中国化和时代化, 不断丰富和 发展科学社会主义理论和原则, 探索社会主义多样化发展路径。

\section{3 从中国特色社会主义再次探索到进入新时代中国特色社会主义}

十一届三中全会开启了中国特色社会主义再次探索的历程。面对中国社会和人民陷入贫 穷的处境, 继续选择过去封闭僵化的老路显然行不通, 走原教旨社会主义道路也行不通, 走 资本主义道路更行不通，因此，中国特色社会主义新路成为历史必然选择。这条道路既可以 保持传统好的东西, 又可以不断改革创新。改革开放的开启, 不断开辟中国特色社会主义道 路向前发展。改革开放之初, 改革的着眼点是如何突破传统社会主义僵化模式, 打破计划经 济和公有制一统天下局面, 解决“挨饿”问题。党通过体制外增量改革，不断激活体制内存量 改革, 打破计划经济和公有制经济的束缚, 引进国外先进技术和管理经验, 调动广大人民群 众的积极性、主动性和创造性。在农村, 实行家庭联产承包责任制, 使得乡镇企业异军突 起，城市个体经济、私营经济、合资经济、外资经济等先后涌现，激发了广大人民的创造热 情, 使他们不断摆脱穷困饥饿状态。党的十三大确立了“三步走”发展战略, “两个大局”发展 思路随后也不断确立起来, 进一步矫正了中国现代化发展目标和战略部署, 推进了社会主义 现代化发展进程。

进入本世纪以来，中国社会继解决“挨饿”问题后，不断面临“挨骂”问题。中国成为世界 第二大经济体后, 国际社会提出了多重挑战, 我们党不断思考发展过程中, 提出了建设社会 主义文化强国的战略目标。党的十八大以来, 党内腐败问题、社会治理问题、军队问题、农 村贫困问题、环境污染问题等不断突显, 考验着党的执政能力。改革开放进入深水区和矛盾 叠加期, 如何啃下硬骨头, 继续坚持改革开放, 提振整个党和军队形象, 重塑党威、军威和 国威, 成为摆在我们党面前的急迫问题。以习近平同志为核心的党中央, 面临“坚持和发展 什么样的中国特色社会主义、怎样坚持和发展中国特色社会主义”基本问题, 针对当时突出 问题，从解决党内“四风”问题入手，不断攻克难题，突破重点，整体推进，根本扭转了党风 政风社风军风, 以中国梦贯通世界梦, 对接外国梦, 激活个人梦, 凝聚起十几亿中国人民的 磅礴力量, 使中国社会豪迈地进入了新时代。

中国特色社会主义进入新时代，与改革开放分不开。改革开放不断促进中国特色社会主 义开创、发展和完善, 成为中国特色社会主义的重要法宝。没有改革开放, 中国社会就不可 能进入新时代。中国的改革开放, 实行渐近改革方式, 通过“摸着石头过河”的试探方法, 不 断试点试验, 然后在此基础上总结经验教训不断宣传推广, 同时确立改革开放的正确方向, 即坚持四项基本原则, 使改革开放既有安全底线又有高远目标。进入新时代以后, 我们党提 出了把顶层设计与摸着石头过河结合起来, 全面深入推进改革开放。总之, 十一届三中全会 后, 改革开放使人民群众从中不断得到好处, 从而焕发出人民群众改革的热情, 不断推进改 革开放向纵深发展，推动中国特色社会主义不断向前发展壮大。

\section{3.新中国成立以来中国社会发展的经验与启示}

\section{1 把科学社会主义原则和中国实际不断结合起来}

恩格斯曾经指出: “不存在任何最终的东西、绝对的东西、神圣的东西。”[19]科学社会主 义原则应当与各国实际结合起来。邓小平也明确指出: “绝不能要求马克思为解决他去世之 后上百年、几百年所产生的问题提供现成答案---真正的马克思列宁主义者必须根据现在的情 况, 认识、继承和发展马克思主义。”[20]马克思晚年提出跨越资本主义制度“卡夫丁峡谷”问 
题。新中国成立后, 面临我国社会工业化基础薄弱情况, 我们不断发展马克思列宁主义, 提 出了新民主主义社会建国方案。为了更好提升我国工业化水平, 摆脱经历资本主义制度的阵 痛, 我们又进行了社会主义改造, 确立起了社会主义制度, 这是科学社会主义原则与我国实 际相结合的产物。但是, 1956 年进入社会主义初级阶段后, 我们既脱离了科学社会主义原 则, 又脱离了中国社会实际, 违背了“相结合”的原则, 不切实际地提出了跑步进入共产主义 的方针政策，使我国社会远离了现代化生产力发展轨道。改革开放后，我们重新倡导“相结 合”原则, 从而扭转了现代化发展的不利局面, 使我国社会主义焕发了生机。实践证明, 把 科学社会主义原则与中国社会实际不断结合起来, 才能找到中国自己的正确道路。中国特色 社会主义理论是我们改革开放以后探索的成果, 它“坚守马克思主义的开放和实践品格, 坚 持马克思主义现代性批判的根本精神”,[21]，指导中国特色社会主义实践获得了巨大成功，并 推动其不断发展壮大。

\section{2 正确处理文化建设与经济政治的关系}

毛泽东在新民主主义革命时期，曾经精辟地指出文化与经济政治的关系，即：“一定的 文化 (当作观念形态的文化), 是一定社会的政治和经济的反映, 又给予伟大影响和作用于 一定社会的政治和经济; 而经济是基础, 政治是经济的集中的表现”[22]。新中国成立以后， 中国社会主义文化建设经历了一番曲折, 我们曾一度把思想政治文化夸大化和绝对化, 使其 脱离了我国社会主义经济基础, 致使生产力遭到破坏。实践证明, 脱离文化与经济政治的关 系，把文化单一化、孤立化甚至政治化是错误的，这不仅不能使文化发挥为经济政治服务的 功能, 反而对其有破坏作用。马克思曾经讲到: “不是人们的意识决定人们的存在, 而是人 们的社会存在决定人们的意识”[23]。“灵魂深处闹革命”还需与物质利益结合起来，简单强化 精神思想的作用是行不通的。文化建筑在经济和政治基础之上，单一的文化革命和建设行不 通, 必须把文化革命与经济政治改革结合起来。改革开放后, 我们把文化与经济和政治紧密 结合起来, 使社会主义精神文化发挥了重要作用。进入本世纪, 文化越来越渗透到经济和政 治活动中, 文化软实力在经济社会发展中发挥了重大作用, 使中国社会发生了巨变, 中国特 色社会主义不断进入新境界。历史证明, 脱离经济与政治, 甚至把文化当作阶级斗争和政治 斗争的工具是不可取的。中国特色社会主义文化的建设和发展, 应当与中国特色社会主义经 济、政治、社会、生态和科技等充分融合起来，以促进和实现社会的全面进步。

\section{3 坚持“四个自信”}

坚定中国特色社会主义理论自信、道路自信、制度自信、文化自信，既是马克思主义中 国化的要求和产物, 也是中国特色社会主义探索成功不断发展壮大的秘码。实践证明, 什么 时候我们坚持这“四个自信”, 什么时候我们的建设和改革就能顺利发展, 否则就会埅入自卑 或自负处境。“四个自信”中, 文化自信尤其重要, 它决定了道路自信、理论自信和制度自 信，是它们的支撑和灵魂。文化自信既不是“文化自卑”，也不是“文化自负”，是对自身文化 发展方向及其来龙去脉有个正确认知和自觉把握。新中国成立至“文化大革命”时期, 我们对 中国文化没有正确认识，在全盘否定本国传统文化的同时，全盘否定了西方优秀文化成果， 把马克思主义教条化、孤立化, 致使我们走向盲从。改革开放之初, 我国掀起了新一轮西方 文化崇拜热潮, 一时陷入文化自卑阴影。本世纪以来, 文化在各国发展中的作用不断突显, 我国文化建设也走向了正轨。为了发挥文化建设的巨大作用，我们党提出了文化自信问题。 坚定中国文化自信, 不是一味模仿和嫁接别国文化和发展模式, 而是我们要有自信去创新自 己的理论、探索自己的道路、发展自己的制度。为此, 我们要实行“两创”方针, 大力弘扬中 国优秀传统文化, 不断坚信文化自信的根基。中国优秀传统文化, 具有开放包容、实事求 是、经世致用和与时俱进的特性, 讲求忠恕之道、先忧后乐、己所不欲、勿施于人等, 如果 能够“按照这些观念去做, 中国社会必会更有秩序、更有诚信一些”[24]。坚定中国文化自信, 还要不断继承和弘扬革命文化, 发展社会主义先进文化, 不断壮大中国文化的根基。中国文 
化是在继承本来、吸收外来、面向未来中不断厚植起来的, 它为我们的道路、理论和制度的 探索打下坚实根基。同时, 还要不断创新理论, 探索新路, 健全制度, 使它们成为中国社会 发展的牢固支柱。

\section{4 坚定走自己的道路}

新中国成立以来的历史告诉我们，照搬照抄别国经验、模式，甚至不顾实际实行赶超战 略是行不通的。邓小平因此指出, “把马克思主义的普遍真理同我国的具体实际结合起来, 走自己的道路，建设有中国特色的社会主义”[25]。从邓小平到习近平，中国特色社会主义在 立足中国、融入世界中，不断改革创新，坚定走自己路的方向中，得到了不断发展。坚定走 自己的道路, 这既是马克思主义的要求, 因为从来“解放我们自己的事业还是要靠我们自 己”, 也是中国社会发展的经验教训。一方面, 要坚定正确的发展方向, 一方面要坚持改革 创新, 不断推进马克思主义中国化。中国特色社会主义是一项前无古人的事业, 照搬照抄不 行, 不进行改革创新也不行, 要在不断改革创新中坚定自己的路。中国特色社会主义道路, 既不是对传统社会主义原则的固守, 也不是对社会主义制度改弦易旗, 要牢牢把握改革开放 的社会主义方向，把握好改革开放的力度。中国社会主义改革，既没有可以奉为金科玉律的 教科书，也没有可以对中国人民䝠指气使的教师爷，需要我们自己去探索，不能靠外界的恩 赐甚至教师爷的指使。正如习近平指出, “改什么、怎么改必须以是否符合完善和发展中国 特色社会主义制度、推进国家治理体系和治理能力现代化的总目标为根本尺度, 该改的、能 改的我们坚决改, 不该改的、不能改的坚决不改。”[26]为此, 我们要增强政治定力, 保持战 略信心，改革创新，探索出属于我们自己的发展道路，才能有底气坚定自己的路。

\section{5 实现国家复兴和人民幸福有机统一}

新中国成立以后，我们曾经一味注重国家积累和国家建设，却忽视了人民群众生活水平 的提高和物质需求, 实际上既没有实现民族复兴, 又没有实现人民生活幸福。实践证明, 单 一强化国家建设，而忽视民众利益需求和生活水平改善，这样的发展最终会导致国家和人民 的共同贫穷，使人民对社会主义失去信仰，对党失去信任，对未来失去信心。改革开放以 后，我们党掀起了改善人民生活处境的伟大改革开放活动，通过民生社会建设促进国家建设 和民族复兴，使我国不断走向富裕。为人民服务是我们党自成立以来的初心和使命，我们只 有不忘初心、牢记使命, 才可能赢得人民群众源源不断的支持力量, 否则我们党便会失去人 民群众的根基。为此, 党要及时地不断地满足人民群众的期盼和要求, 给人民群众不断带去 福音, 党才可能做好工作, 干成事业, 实现领导。改革开放以来的实践, 正如习近平指出: “从根本上说，没有扎扎实实的发展成果，没有人民生活不断改善，空谈理想信念，空谈党 的领导, 空谈社会主义制度优越性, 空谈思想道德建设, 最终意识形态工作也难以取得好的 成效。”[27]这也是对改革开放前社会主义建设历史教训总结的结果。改革开放以来，尤其是 十八大以来的历史表明, 只有人民群众的获得感、幸福感、安全感不断增强, 我们党才可能 获得持久的力量和支持，国家建设才能有坚实的根基。国家强大，民族复兴，离开人民的幸 福不行，只有把二者有机统一起来，才可能实现国强民富。

\section{6 正确推进“两个伟大革命”}

党要正确实现领导，既不能跟在人民群众屁股后面亦步亦趋，也不能高高站在人民群众 头顶发号施令, 而是深入群众中间, 倾听群众呼声，关心民瘼，回应群众要求，满足群众期 盼, 在推进伟大社会革命中, 实现自身的伟大革命, 以适应国家、民族和时代发展需要。历 史表明, 党不能适时地进行社会改革以及自身改革, 或者使两者走上错误轨道, 都不能实现 正确领导，党的事业因此也会遭受损失。改革开放以后，我们党协调推进“两个伟大革命”, 使中国社会获得源源不断的生机和动力。尤其是十八大以来，习近平在总结历史基础上，不 断回应现实问题挑战, 以战略思维谋全局, 以辩证思维解矛盾, 以法治思维图善治, 以系统 
思维聚合力, 以底线思维定边界, 以创新思维增活力, 以开放思维拓视野, 以党的自我革命 不断推进和强化社会革命, 谱写了中国特色社会主义新篇章。习近平指出, 我们要牢记“李 自成的历史教训”，牢记“两个务必”，牢记“生于忧患，死于安乐”的古训，着力解决好“其兴 也勃焉，其亡也忽焉”的历史性课题。他要求全党增强管党治党的自觉，提高党的执政能 力和领导水平，增强党自我净化、自我完善、自我革新、自我提高能力 ${ }^{[28]}$ 。统筹推进 “两个伟大革命”，实现党的正确领导，才能实现中华民族伟大复兴的梦想。

\section{致谢}

本文系绵阳师范学院引进人才科研基金资助项目(课题编号: QD2012B06)的阶段性成果 之一。

\section{References}

[1] Selected works of Mao Zedong, People's Publishing House, vol.4, pp.1439,1991.

[2] Cheng Weili and Dai Xuemei, Thought history of socialist with Chinese characteristics, Xuelin Publishing House, pp.3,2009.

[3] Selected works of Mao Zedong, People's Publishing House ,vol.2, pp.675-676,1991.

[4] Wang Zhanyang,Mao Zedong's strategy of founding the People's Republic of China and the reform and opening up of contemporary China, Jilin People's Publishing House, pp.137139,1993 .

[5] Anna Louise Strong, Chinese conquer China, Beijing Press, pp.147,1984.

[6] Selected works of Mao Zedong, People's Publishing House,vol.5,pp.34,1977.

[7] Selected works of Mao Zedong, People’s Publishing House,vol.1,pp.160-161,1991.

[8] Selected important documents since the founding of the People's Republic of China, Central Literature Publishing House, vol.1,pp. 231,1992.

[9] A manuscript letter to Tian Jiaying by Bo Yibo In 30 December 1965.

[10] Selected materials of economic archives of the People's Republic of China: comprehensive volume, Chinese Urban Economic and Social Publishing House, pp.776-779,1990.

[11]Yang Jiazhi, The primary stage of socialism and return of the development model of New Democracy, Journal of Central South University of Finance and Economics, vol.5,pp.1,1994.

[12] Selected works of Mao Zedong, People's Publishing House, vol.5,pp.182,1977.

[13] Selected works of Mao Zedong, People's Publishing House, vol.4,pp. 1481,1991.

[14]Reference material for the history of the Communist Party of China, People's Publishing House, vol.8,pp.49,1980.

[15] Mao Zedong's manuscript since the founding of the People's Republic of China, Central Literature Publishing House, vol.4,pp. 390-391,1990.

[16]A collection of Mao Zedong's works, People's Publishing House, vol.8,pp.117,1999.

[17]Bo Yibo,A review of a number of major decisions and events, The Party School of the CPC Central Committee Publishing House, vol.1,pp.472,1991.

[18]John King Fairbank, History of the People's Republic of China, Cambridge(19491965), Chinese Academy of Social Sciences Press, pp.130,1990. 
[19] Selected works of Marx and Engels, People's Publishing House, vol.4,pp. 223,2012.

[20] Selected works of Deng Xiaoping, People's Publishing House,vol.3,pp.291,1993.

[21]Zhou Feng,Marxism and the problem of Chinese modernization, Shandong Social Sciences, vol.12,pp.27,2016.

[22] Selected works of Mao Zedong, People's Publishing House, vol.2, pp. 663- 664,1991.

[23] Selected works of Marx and Engels, People's Publishing House, vol.2,pp.2,2012.

[24]Chen Jin,Cultural self-confidence and Chinese Road, Xinxiang Review,vol.9,pp.15,2016.

[25] Selected works of Deng Xiaoping, People's Publishing House, vol.3,pp.3,1993.

[26]Xi Jinping,Speech at the general assembly to celebrate the 40th anniversary of reform and opening up,http://politics.people.com.cn/n1/2018/1219/c1024-30474898.html.

[27]Xi Jinping talks about "the essentials of rejuvenating the country": development is the key to solving all problems, http://cpc.people.com.cn/xuexi/n1/2017/0615/c385474-29340955.html.

[28]Xi Jinping,Speech at the Symposium to commemorate the 120th anniversary of Comrade Mao Zedong's birthday,http://www.xinhuanet.com//politics/2013-12/26/c_1187234. 